\title{
Approach to Healing Environment at A Heart Hospital in Surabaya
}

\author{
M H Syaifudin ${ }^{1}$, W W Widjajanti ${ }^{1}$, E Poedjioetami $^{1}$ \\ ${ }^{1}$ Architecture Departement, Institut Teknologi Adhi Tama Surabaya, Indonesia \\ mochhusnisyaifudin@gmail.com
}

\begin{abstract}
Cardiovascular disease is the leading cause of death nearly $30 \%$ people around the world is caused by heart disease which comes from $80 \%$ poverty and developing countries. For Indonesia, cardiovascular disease also holds the record of non-communicable diseases with the highest case, especially East Java which is included the second predicate as the province with the largest heart disease. With the high mortality rate that occurs, it needs to plan a building that can be a service heart disease supporting the ideal healing process. Healing environment approach can pay attention to hospital building/hospital design which gives positive effect both physically and psychologically can make the healing process within the hospital itself. With the take this approach is considered in the heart hospital in Surabaya can make the hospital that can support the healing process optimally. The final result of heart hospital design in Surabaya with healing environment concept, the design of heart hospital to adjust to the environment around the site by putting forward three design approaches that are nature, senses, and psychological. With the heart hospital in Surabaya is expected to give benefits to the community in the face of heart disease is increasing from year to year.
\end{abstract}

\section{Introduction}

\subsection{Background}

Modern life has become a top priority for most people in Indonesia, especially the middle to upper economic community. People in modern times today are busy pursuing their everyday needs that are all practical and completely automated. Such lifestyle results in an increased risk of heart attack. Cardiovascular disease is the leading cause of death mostly around the world. According to WHO, $30 \%$ death worldwide is caused by heart disease and more than $80 \%$ coming from poverty and developing countries.

In Indonesia, there are three hospitals handling heart disease. There are three adequate hospitals, national heart hospital, Binawaluya Heart Hospital, and Jakarta Heart Center, but the three hospitals in Jakarta. Based on the results of Basic Health Research (2013) conducted by the Ministry of Health RI the highest prevalence of heart failure in DI Yogyakarta $0.25 \%$, followed by East Java $0.19 \%$, and Central Java $0.18 \%$.

In the journal Creating Healing Environments Through the Theory of Caring (2016, Vol. 104, No. 5) says the Watson theory of the environment is the embodiment of patient healing. Cultivating a caring environment is essential for the healing of patients and nurses. Healing with the environment then the patient can receive positive energy and more attention so that the healing period is faster. Complementary Therapy in Nursing \& Midwifery (I 996) 2, I1 0-115 also says the environment is a 
possible aspect, but current treatments give a low priority due to hospital design. Industrial model. By presenting a visual environment, garden and indoor plantings and tables can make the hospital much more enjoyable. An assessment of the importance of environmental aspects can give significant benefits. In this hospital will apply the concept of healing on the design of the land, space and shape so that it can make healing from environmental aspects. Then this condition illustrates that the need for heart hospitals that promote environmental aspects as a healing and for the service of heart disease can be equitable and fulfilled, especially in the eastern region. This hospital will be planned in East Java, especially in Surabaya. Heart hospital in Surabaya is expected to give benefits for the people of East Java in the face of heart disease is increasing from year to year.

\subsection{Problem Statement}

How to create a specialized heart hospital building that supports optimal healing process in accordance with the healing environment approach. Applying the Healing enviroment approach so that it is expected not only doctors and medicines can help healing, but also the environment, especially the hospital environment affect the recovery of patients. Application of healing environment in arranging space that can support the patient in the healing process. How to arrange a circulation path between many patients with heart disease that is in dire need of fast handling between visitors, patients and hospital medical hospitals themselves.

\section{Materials and methods}

This design is guided by hospital technical guidelines, and Minister of National Health Services, Regulation and Coordination combined with comparative study to look for architectural paradigm, to produce hospital design parameters.

\subsection{Heart Hospital}

According to Minister of National Health Services, Regulation and Coordination no. 340/MENKES/ PER/III/2010 on Hospital Classification, Cardiovascular Hospital is included in Specialized Hospitals, ie hospitals that offer primary services in one area or one particular type of disease, based on discipline, age group, organ or type of disease, in this case the service to the type of heart disease and associated with the heart (cardiovascular)

\subsection{Environmental architecture}

According to Y.B Mangun, the environmentally sound architecture focuses on a work of architectural design based on aesthetic pressing by taking elements from the surrounding nature that create local local culture and its existence does not confuse the character and condition of the surrounding environment [1].

So the environmentally sound architectural approach taken for the Planning and Design of Heart Hospital in Surabaya is the Healing Environment. In which it can be defined as the environment or conditions that support the healing process and efforts to be healthy and thorough again. With the take this approach is considered in the heart hospital in Surabaya can make the hospital that can support the healing process optimally. According to Murphy (2008) there are three approaches used in designing healing environment, namely nature, psychological indradan.

\subsection{Data Source and Design Method}

The process of planning and design used is descriptive research, field case study and literature, ie research that aims to present a picture of phenomena or social reality, symptoms, common done by survey methods, interviews, observations, case studies, correlation studies, case study data, site and space with pragmatic and programmatic methods. Collect data sources on site and site designations, as per RDTRK (Detailed Spatial Plan). After it has been analyzed the next stage, the synthesis of data produces design concept along with the transformation of the concept. Then it will be redeveloped to final design. 


\section{Result of Data Analysis}

\subsection{Healing Environment}

The concept of healing environment involves the patient in the process of conscious self-healing and mental development. Space is designed for treatment and therapy and, most importantly, to reduce stress. It is a research-based approach to design (also known as evidence-based design), which aims to relieve stress because of the environment and puts the patient in contact with nature in regular treatment. The design of the physical setting of the environment has a healing environment in the heart hospital which has the effect of eliminating environmental stress such as noise, glare, lack of privacy and poor air quality, connecting patients to nature without scenery, providing opportunities for social activities - providing privacy for family groups, accommodation for family members or friends in medical settings, "stay" accommodation for families in patient rooms, giving birth to feelings of peace, hope, reflection and spiritual connections and providing opportunities for relaxation, education, humor and imagination.

In 1984, Roger S Ulrich, architect and architectural professor at Texas A \& M University, examined the patient's clinical impact on a room with windows facing the outside environment in his journal View through a window may influence recovery from surgery. In the journal Ulrich reveals that patients with windows facing the natural landscape have short hospital days, fewer negative evaluations (about health conditions) than nurses, there may be lower postoperative complications.

From the description of the theory and the results of research experts on the Healing Environment we can conclude that giving attention to the design of buildings / hospital environment that gives positive effects both physically and psychologically can streamline the healing process within the hospital itself. According to Murphy (2008), there are three approaches used in designing healing environment, namely nature, senses and psychological.

\subsection{Space Requirements Analysis and Site Analysis}

Tabel 1. Space needs

\begin{tabular}{clc}
\hline $\begin{array}{c}\text { Classification } \\
\text { of functions }\end{array}$ & \multicolumn{1}{c}{ Category } & Total area m2 \\
\hline Primary & Outpatient (Poly Heart), Inpatient & 31555,25 \\
\hline Secondary & $\begin{array}{l}\text { Operation, ICU, Nutrition Room, Receptionist, Pharmacy, } \\
\text { Laboratory, Photo Thorax, Bodies, Warehouse, Medical gas }\end{array}$ & 671,55 \\
\hline Support & $\begin{array}{l}\text { Musholla, Garden, Mechanical engineering (me), Landfill, } \\
\text { Laundry, Guest accommodation, Cleaning service, Toilet, } \\
\text { Cafeteria, Parking, Security post, Incenerator Room, ATM }\end{array}$ & $\begin{array}{c}999,45 \\
\\
\end{array}$ \\
\hline & Total & $\begin{array}{c}33226,25 \mathrm{~m} 2 / 3,3 \\
\text { ha }\end{array}$ \\
\hline
\end{tabular}

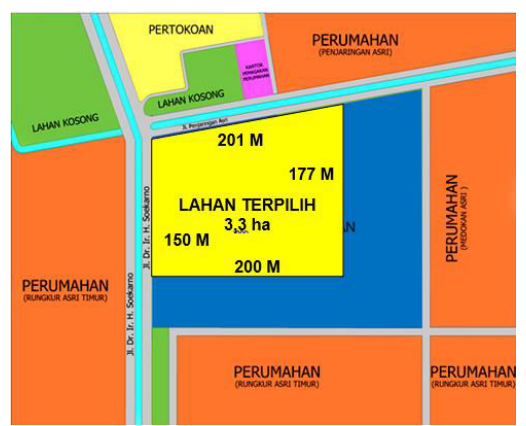

The boundaries of the project area, among others

- North : Jl. Penjaringan Asri

- West : Jl. Dr. Ir. H. Soekarno

- South : Rungkut Asri Timur Real Estate

- East $\quad$ : Medokan Asri Timur Real Estate

Figure 1. Picture of selected land (Source: https://www.google.com/maps) 
It is located on Jl. Dr. Ir. H. Soekarno (Rungkut Asri), East Surabaya. The reason for choosing this site is easy to reach out, the site is among the residential area of the community with the upper middle and lower middle social levels, the growing area, which in terms of apartment development, and housing in the area, is on the primary arterial road, easily accessible to visitors on a local and regional scale, easily accessible from public hospitals.

\subsection{Concept design}

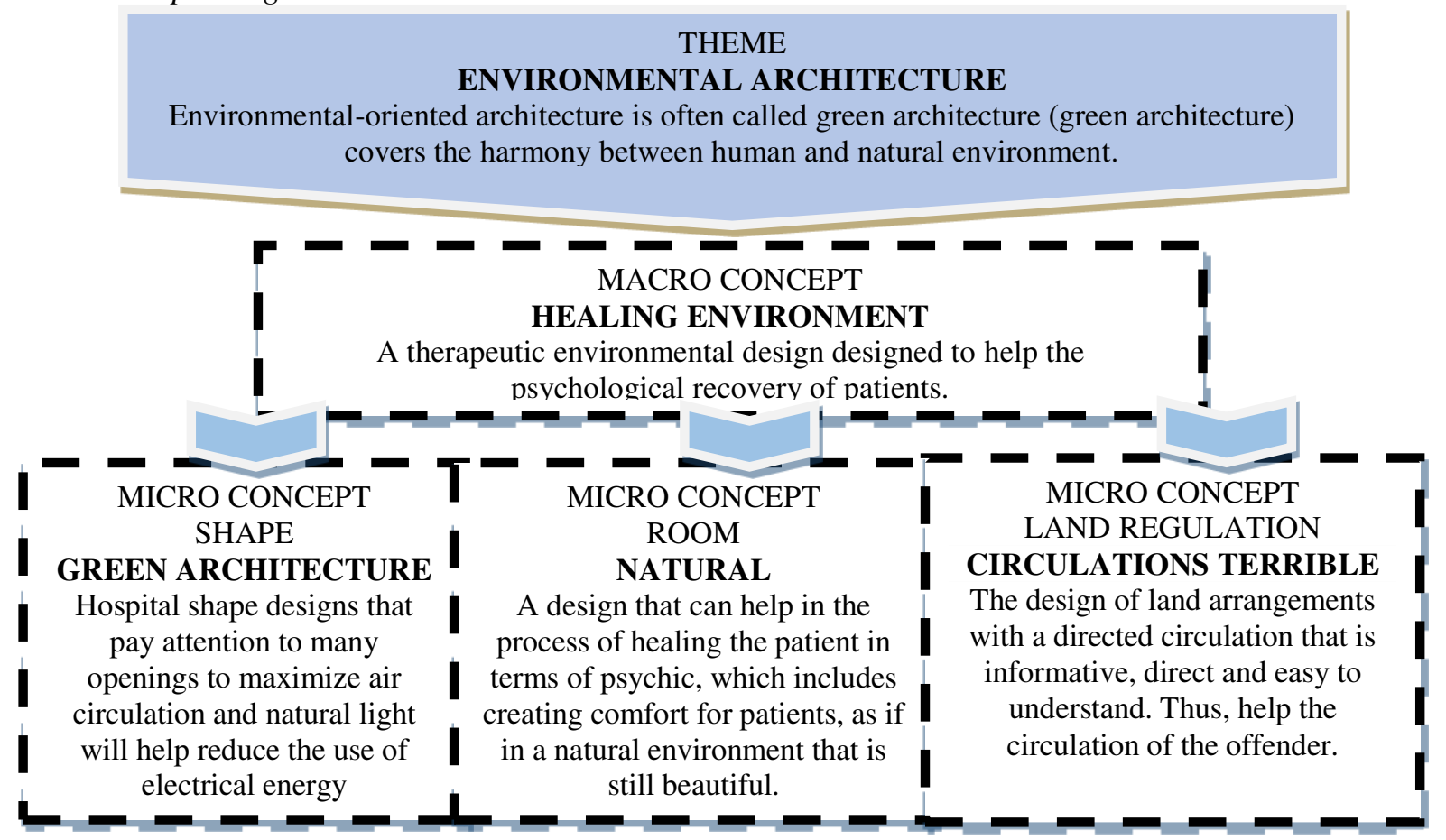

Figure 2. Hirarki concept (Source: Personal analysis)

3.3.1 Shape design. The shape of this heart hospital building uses the concept of Green architecture, which in the form of processing attention to building design strategies that use the concept of green architecture.

The shape of the building is chosen from the square and rectangular shape. Long because it has a rigid, systematic, static, and oriented nature. These properties are very suitable to be applied to hospital buildings because of the flow of user activity in it directionally and systematically. Related to the concept of Healing Environment, in the form of square and rectangle is done by subtraction and addition to creating a healing garden. 


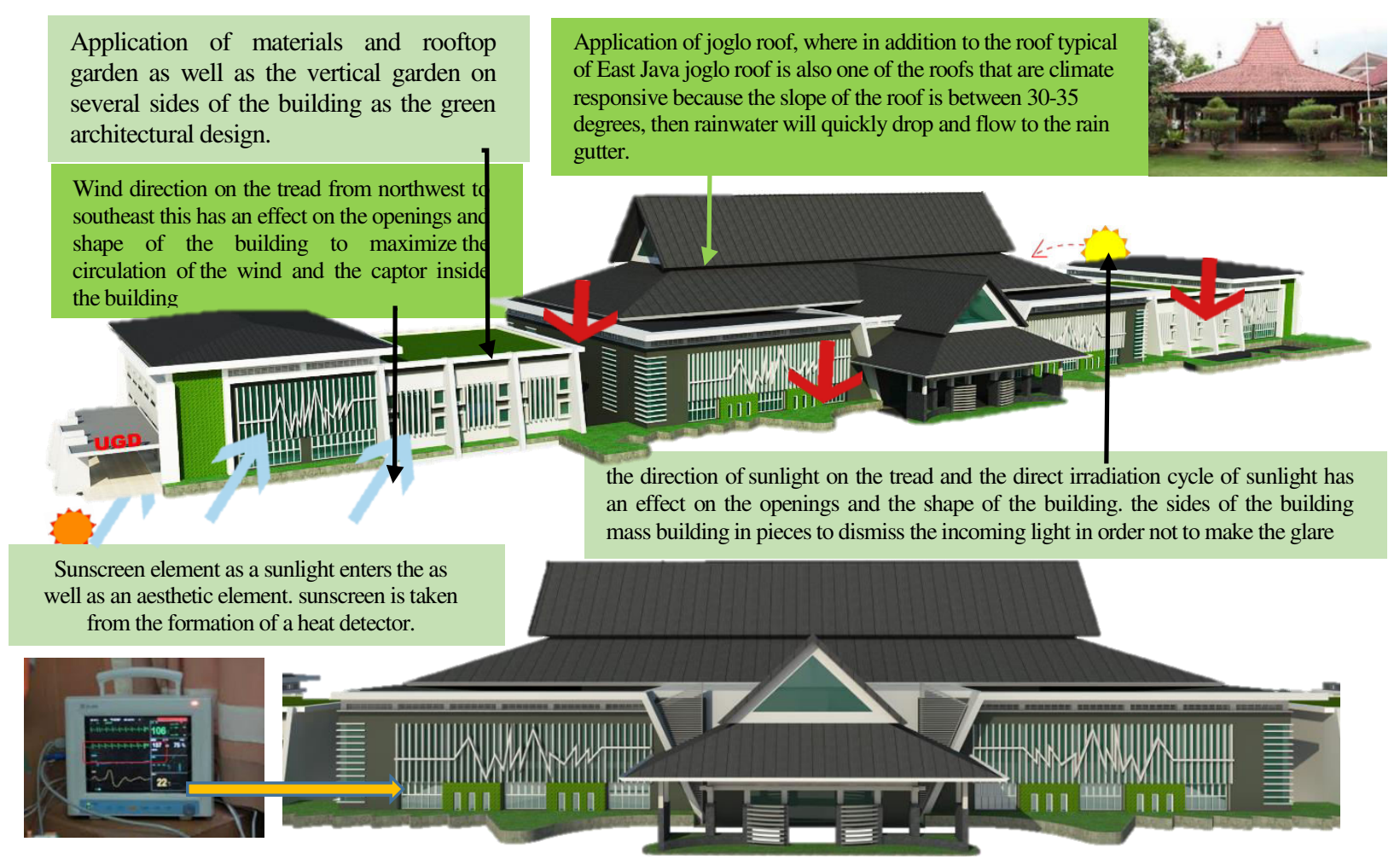

Figure 3. Shape design (Source: Personal design)

3.3.2 Room design. The interior of the building adopts many concepts of nature and the senses as the hallmark of the "natural" concept in which space can be felt, seen, touched, and heard so well that it creates a feeling of comfort. The use of wood dominant materials in interior spaces is one way to realize the concept of "natural" by promoting the Healing Environment approach. To support the color to make natural color then apply the color in nature, not the color of the processed. The color of the soil, branches, wood, and color of plants can be applied to the design of natural space.
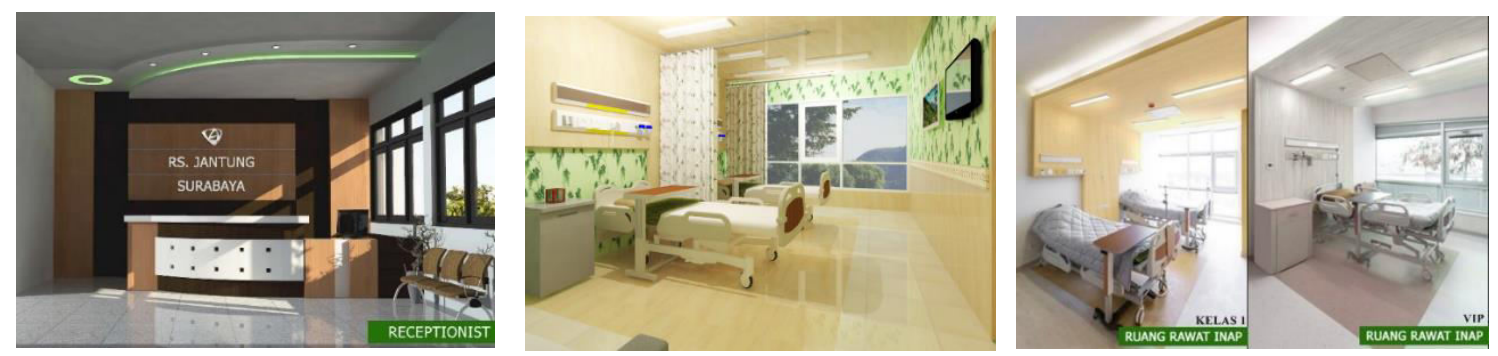

Figure 4. Room Design (Source: Personal design)

3.3.3 Land regulation design. The concept of building design with a system approach basically refers to the Hospital Building Technical Guidelines set by the Ministry of Health of the Republic of Indonesia. The proximity of the spaces within it is formed based on the flow of circulation of activities performed by hospital users.

The Building Special Hospital consists of 7 masses called Building A, B, C, D, E, F, G. Building A from Emergency Unit, Building B Outpatient and equipped with Pharmacy Installation and facilities supporting like a bank, while the second floor in the use of hospital management room, meeting room and hospital auditorium. Building C therapy, Building D from Operation Room, OK Room, Radiology 
Installation, Medical Rehab Installation, Laboratory, Building E, F are used for inpatient rooms. Building G is used as service installations such as Central Sterilization Installation / CSSD, Nutrition Installation, Laundry Installation, Space of the Bodies Here is a description of the placement of space in a special heart hospital building planned:

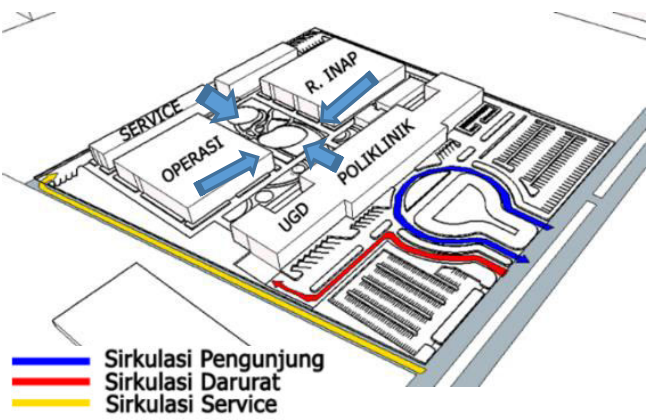

All view of the building at this hospital at one point that is in the park in the middle of the Healing Garden or park to help the healing process As a supporter of park hospital activities should contain elements that indirectly give stimulus to help the healing process of patients, it positively affects both hospital staff and patient families.

Using a radial circulatory system characterized by the existence of a central point of purpose or origin of the movement of this pattern is formal and dominant. This pattern is used because the hospital is formal and must be clear circulation because the demand has a fast \& clear circulation.

Figure 5. Land regulation design (Source: Personal design)

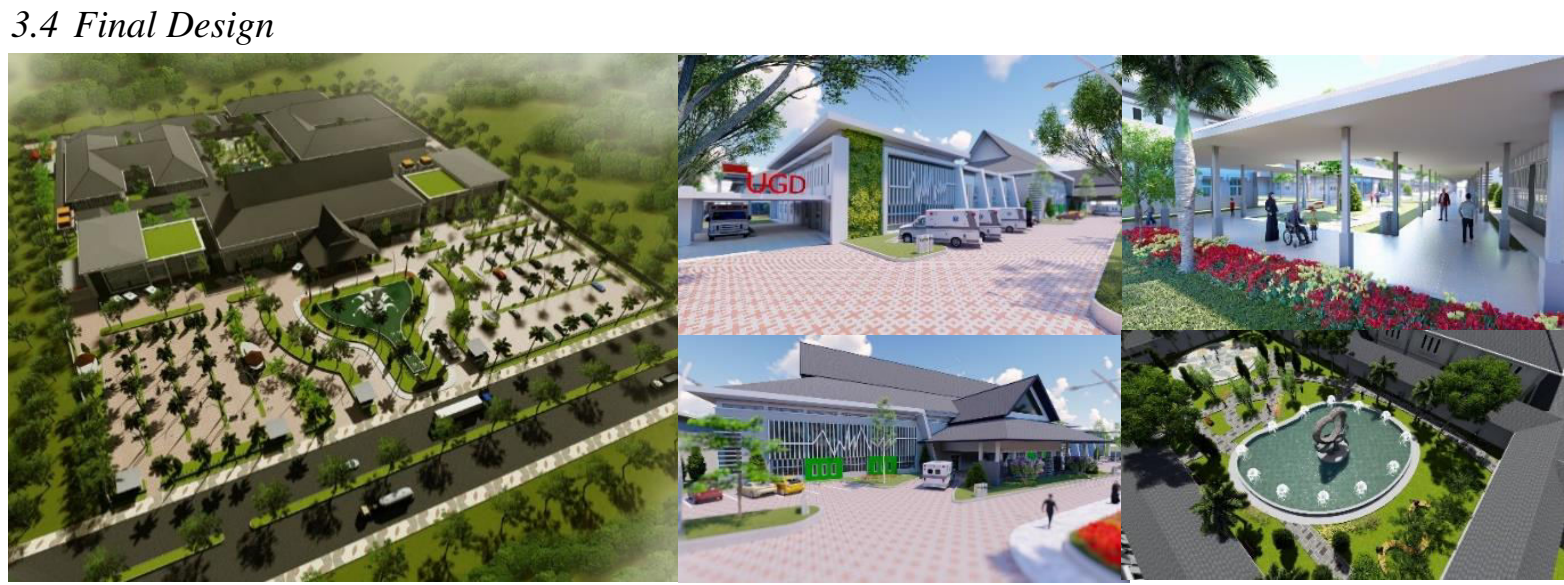

Figure 6. Perspective design of heart hospital in Surabaya (Source: Personal design)

\section{Conclusion}

Based on the process of approach to healing environment at heart hospital in Surabaya has been done then the conclusions are obtained such as: Designing a Cardiovascular Hospital creates a comfortable condition for the patient as well as for the delivering family, by providing architectural design solutions according to the heart hospital function as a complete facility. Helping the environment and attractive buildings that can support the healing of patients with heart disease physically and psychologically by the theme of Environmental Oriented Architecture. Applying the hospital's shape with the Healing Environment approach according to the theme of "Environmentally Friendly Architecture".

\section{Reference}

[1] Y. Mangunwijaya, “Teknologi dan Dampak Kebudayaan I.” Jakarta, 1983. 